7. Child Lang 25 293-319. Printed in the United Kingdom

(C) 1998 Cambridge University Press

\title{
The acquisition of plural marking in English and German revisited: schemata versus rules*
}

\author{
KLAUS-MICHAEL KÖPCKE \\ (University of Hannover) \\ (Received 2 September 1996. Revised 19 May 1997)
}

\begin{abstract}
\end{abstract}
This article contributes to a debate in the linguistic and psychological literature that centres around the representation of morphologically complex words in the grammar and in the lexicon. The issue is whether inflectional morphology is rule-based (i.e. symbolically represented), or whether the assumption of pattern association is more adequate to account for the facts. On the basis of the analysis of acquisitional data the article strongly argues for the latter alternative. In a classic experiment that helped shape the development of acquisition theory Berko (I958) reported substantial support for ITEM-AND-PROcEss rules in the acquisition of plural morphology in English. A large part of her results were zero responses (repetition of the stimulus). A reinterpretation of these zero responses in light of schema theory and the cue strength hypothesis shows a striking departure from randomness. Berko's subjects tended to repeat stimuli just to the extent that these already resembled a plural schema. A reinterpretation of data reported in Innes ( 1974) achieved compatible results. This data set is far more extensive than Berko's and is used in the present study to put the schema model to a more stringent test. A reinterpretation of a parallel experiment with German children, using the cue strength analysis of the more complex plural morphology of German yielded parallel results. Finally, natural acquisitional data obtained from seven German speaking children aged between 2; I and 2; 9 are analysed. Again, strong support is found for the schema model. It is suggested that a schema-learning mechanism may underlie the acquisition of morphology, even when the end product of the learning process involves item-and-process rules, as in the case of English plural formation. In a schema-learning model, the child builds schematic representations for possible singular and plural lexical items

[*] My thanks are due to David Zubin (Buffalo) for his invaluable ideas and comments on earlier versions of this paper. Address for correspondence: Klaus-Michael Köpcke, Universität Hannover, FB Erziehungswissenschaften I, Bismarckstr. 2, 30I73 Hannover Germany. 
as whole gestalts, and attempts to map concrete forms onto these schemata in deciding whether the forms have singular or plural value.

\section{INTRODUCTION}

An almost classical debate in linguistics and psychology concerns the question of how morphologically complex words are represented in the grammar and in the lexicon. For a long time the inflectional system for English verbs was seen as a paradigmatic case for the assumption that complex words are formed by rules that concatenate morphemes. With a few exceptions all English verbs form their past tense by adding the morpheme -ed. These rule-governed items contrast with those which have to be stored as exceptions in the lexicon, e.g. go or write.

This polar distinction between the grammar on the one hand and the lexicon on the other was challenged in the last ten to fifteen years by an anticlassical approach to categorization, i.e. prototype theory, a model of categorization inspired by the psychological experiments conducted by Eleanor Rosch since the seventies (see Rosch I977, I978). Rosch assumes that members of natural classes of objects, e.g. birds or furniture, are organized around 'prototypical' examples in the centre of the category. The prototypical instances are defined by a maximal number of attributes. Rosch hypothesizes that a category is mentally not represented through abstract attributes but through more concrete typical instances, i.e. 'best exemplars' of the category. The category is not characterized by binary contrastive features but rather by a number of properties. Consequently, a distinction has to be made between central and peripheral members of a class. The members of a class are distributed across a continuum. At one pole of this continuum those category members are located which are defined by a maximal number of properties; the opposite pole represents those members which have only one or very few of the relevant properties characterizing the prototype. Such members are thus located at the periphery of the category and they might easily lose their category membership in one class and be reassigned to a contrastive category. The members of a category are not regarded as a homogenous set: rather, they are representative of the category as a whole to varying degrees. A model that operates with criterial features requires that every member of a category exhibit all the features of the category whereas the prototype approach only assumes that the members of a category exhibit a lesser or higher degree of 'family resemblance' with the prototype.

There is no doubt that linguistic signs belong to 'natural' classes in the sense sketched above. The language user is under constant pressure to categorize and classify linguistic items and it is plausible to assume that these 
categorizations proceed along lines analogous to the principles found in the categorizations of non-linguistic phenomena. Bybee \& Moder ( $1983: 267$ ) assume that 'speakers of natural language form categorizations of linguistic objects in the same way that they form categorizations of natural and cultural objects', consequently, 'the psychological principles which govern linguistic behaviour are the same as those which govern other types of human behaviour'. Data which were suggestive for this conclusion again came from English verb morphology. There are some strong verbs in English that show the vowel alternation $[\mathrm{I} /-/ \mathfrak{x} /-/ \Lambda /$ by changing from the present tense to past tense and past participle, e.g. sing-sang-sung. The pattern $/ \mathrm{I} /-/ \Lambda /-/ \Lambda /$, e.g. as in cling, shows close resemblance with the former. Both patterns were so productive they even attracted members of other classes to switch class membership, e.g. ring. It was not even required that /I/ be the stem vowel in the present tense, e.g. hang. Table $\mathrm{I}$, which is taken from Taylor (I 995: I 75), shows that the classes exhibit a prototype structure.

TAвLE I. Properties of English strong verbs having $/ æ /-/ \Lambda /$ or $/ \Lambda /-/ \Lambda /$ in past tense and past participle

\begin{tabular}{lccc}
\hline & $\begin{array}{c}/ \mathrm{I} / \text { in } \\
\text { present tense }\end{array}$ & $\begin{array}{c}\text { Velar as final } \\
\text { consonant }\end{array}$ & $\begin{array}{c}\text { Nasal as final } \\
\text { consonant }\end{array}$ \\
\hline sing & Yes & Yes & Yes \\
cling & Yes & Yes & Yes \\
hang & No & Yes & Yes \\
swim & Yes & No & Yes \\
stick & Yes & Yes & No \\
strike & No & Yes & No \\
\hline
\end{tabular}

By far most of the verbs have a velar nasal as a final consonant, e.g. spring. Other verbs share only partial similarity with the central members, e.g. they have a non-velar nasal as a final consonant (swim). Even more remote from the prototype are those that end in a non-nasal velar, e.g. stick. As a consequence of observations like the one just cited, Bybee (1985, I988, I99 I) has proposed a continuum of schemata extending from irregular to regular morphology. The advantage of such a schema model is that it eliminates the strict division between the grammar on the one hand, which covers regular productive morphology (e.g. how most English verbs and new verbs form their past tense) and the lexicon on the other hand, in which all exceptions to regular processes are stored. If Bybee's position is examined further, then the RULE, a central theoretical concept of most linguistic theories is questioned. Bybee's model closely resembles a connectionist model (cf. Rumelhart \& McClelland (I986) and McClelland (I988)) since both theories 
make the assumption that generalizations arise from patterns in an associative network. Rumelhart \& McClelland ( I986) were able to show that a parallel distributed processing model perfectly simulates acquisitional stages for the past tense form in English, when given input that reflects the type and token frequency of regular and irregular verbs. In the simulation the regularization of the past tense coincides with a sharp increase in the input of regular past tense formations. It must be emphasized here that a parallel distributed processing model does not formulate symbolic rules, rather, just like in Bybee's model, other lexical patterns are accessed, and the strongest of these, which happens to be regarded as being regular in English, at a certain threshold level outnumbers the others.

The counterposition is that the concept of rule is indispensable and that regular inflections are derived by a symbolic rule which operates on an underlying form in order to generate the specifically needed surface form. This position can be found e.g. in Pinker ( 199 I), Marcus, Pinker, Ullman, Hollander, Rosen \& Xu ( г 992), and Marcus, Brinkmann, Clahsen, Wiese \& Pinker (I995). To date, there are two morphological areas from which empirical data have been used to support the two competing models:

(i) verb morphology (cf. among others Bybee \& Slobin (1982), Bybee \& Moder (I983), Clahsen \& Rothweiler (I992), and Marcus et al. (1995));

(ii) plural morphology (cf. among others Köpcke ( 1988, I 993), Clahsen, Rothweiler, Woest \& Marcus (I 992), and Marcus et al. (1995)).

In what follows, evidence and arguments in favour of the schema model will be presented. I shall concentrate exclusively on acquisitional data of English and German plural morphology.

\section{The acquisition of plural marking in English}

In a structural theory of morphology based on an 'Item-and-Process' (IP) model (cf. Hockett ( 1954 )) the plural marking system of English seems to be highly transparent and motivated. Consequently, older generative treatments of noun plural formation in English contain simply an abstract plural morpheme 'item' ( $\mathrm{a}$ ) and morphophonemic rewrite 'process' rules ( $\mathrm{Ib}$ ), producing a set of alternants (cf. also Fromkin \& Rodman (i 974)) :

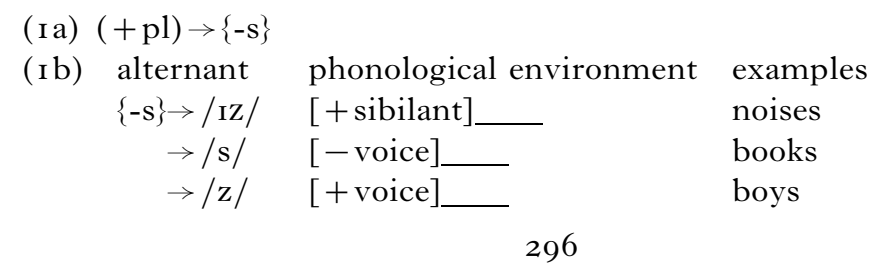


Finally, such traditional analyses contain a list of exceptions marked in the lexicon (Ic):

$$
\begin{array}{lll}
\text { (Ic) ox: } & \text { /aks/ } & \rightarrow \mathrm{pl}: \text { /aksən/ } \\
\text { knife: } & \text { /nayf/ } & \rightarrow \mathrm{pl}: / \text { nayvz/ } \\
\text { goose: } & \text { /gus/ } & \rightarrow \mathrm{pl}: \text { /gis/ } \\
\text { child: } & \text { /čayld/ } & \rightarrow \mathrm{pl}: \text { /čildrən/ } \\
\text { person: } & \text { /persən/ } & \rightarrow \mathrm{pl}: / \text { pipəl/ } \\
\text { deer: } & \text { /dir/ } & \rightarrow \mathrm{pl}:-\emptyset
\end{array}
$$

Such a treatment thus regards the morphological realization of grammatical categories as either categorically regular, as in ( $\mathrm{I}$ a) and ( $\mathrm{Ib}$ ), or as arbitrarily exceptional, as in (Ic), resulting in a dichotomy between absolute regularity and irregularity.

THE BERKO DATA

Method and results

It was this IP model of morphological rules that Berko (1958) addressed in her famous 'wug' experiment on the acquisition of plural marking in English. Her goal was to test for the extent of internationalization of IP rules. To guarantee 'novelty' she used nonsense material for her stimulus items. Berko presented nonce words along with pictures in a task intended to elicit a plural form from her subjects (e.g. "Here is a picture of a "wug". Now there are two of them. There are two __ ?'). She assumed that if a child could master unfamiliar words in the same consistent way as she or he did real, familiar ones, this would demonstrate that the child had mastered some general morphological rule in order to pluralize nouns, which went beyond the knowledge of those specific plural forms to which the child had been previously exposed.

Table 2 (adapted from Berko's table 2) shows the results for the six/sevenyear-olds. ${ }^{1}$ The Table shows that the subjects performed better with nonce words requiring the $\{-z\}$ allomorph than those requiring the $\{-\mathrm{Iz}\}$ allomorph. Only one stimulus (heaf) tested the $\{-\mathrm{s}\}$ allomorph, and this was equivocal, since it allowed either / hifs/ or / hivz/ as normative plurals. Berko accounts for this difference by pointing out that $\{-\mathrm{IZ}\}$ is both phonologically more complex, i.e. the scope of $\{-\mathrm{Iz}\}$ requires an extra rule, namely vowel epenthesis, and furthermore, less frequent as a plural allomorph than $\{-\mathbf{z}\}$.

[I] The data from Berko's four/five-year-olds also tend to support the new analysis given here, but they are less clear, and thus are not reported for the sake of succinct presentation. 
SCHEMATA VERSUS RULES IN PLURAL MARKING

TABLE 2. Distribution of responses for Berko's (I958) data of the six/sevenyear-olds

\begin{tabular}{|c|c|c|c|c|}
\hline $\begin{array}{l}\text { Nonce } \\
\text { word }\end{array}$ & $\begin{array}{l}\text { Expected plural } \\
\text { allomorph }\end{array}$ & $\begin{array}{l}\text { Correct } \\
(\%)\end{array}$ & $-\emptyset(\%)$ & $\begin{array}{l}\text { Other deviant } \\
\text { form }(\%)\end{array}$ \\
\hline wug & $|-z|$ & 97 & 3 & - \\
\hline lun & $|-z|$ & 92 & 8 & - \\
\hline tor & $|-z|$ & 90 & IO & - \\
\hline heaf & $\mid-\mathrm{s} /, /-\mathrm{z} / *$ & 80 & I 6 & 4 \\
\hline cra & $|-z|$ & 86 & I 4 & 4 \\
\hline tass & $|-\mathrm{IZ}|$ & 39 & $6 I$ & - \\
\hline gutch & $|-\mathrm{IZ}|$ & 38 & 52 & IO \\
\hline kazh & $|-\mathrm{IZ}|$ & 36 & 59 & 5 \\
\hline niz & $|-\mathrm{IZ}|$ & 33 & 67 & - \\
\hline
\end{tabular}

* For the nonce word heaf two alternants of the plural morpheme $\{-\mathbf{s}\}$ are scored as correct.

\section{A reanalysis of Berko's results}

As a first approximation to a reanalysis of Berko's data consider the pattern of zero responses. In her article Berko does not systematically differentiate zero and non-zero deviant responses, but she does report that the latter are virtually nil. Table 2 gives the frequency of deviant responses minus the nonzero responses reported in the text of Berko's article, yielding a very close approximation of the frequency of zero responses. Figure I shows that the

Highest degree of similarity to plural schemata Lowest degree of similarity to plural schemata

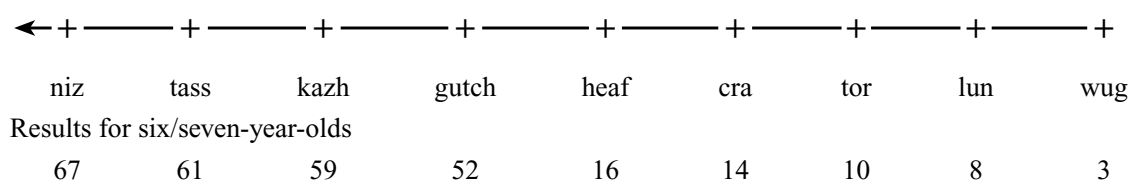

Fig. I. Repetition of stimuli (zero responses) given in percentages and relative similarity to plural schemata.

distribution of zero responses is not random, but that the similarity of test items to plural schemata played a crucial role in performing the task.

The aim of the present study is to show that this distribution suggests a cognitive model of morphological representation containing not only IP rules, but also a schematic component in which morphological rules and lexical representations are not separate. In this component, forms (both morphologically simplex and complex) in the lexicon are individually subsumed under SCHEMATA having a probabilistic, prototype structure (cf. Bybee \& Slobin (1982), Lakoff (r982), Bybee \& Moder (I983), Köpcke \& Zubin (1983), Bybee (1985, I988), and Köpcke (1993)). This structure is determined by the CUE STRENGTH of the schema's individual components, 
which is in turn determined by the salience, frequency, and cue validity of these components. The schema model is placed somewhere between traditional IP formulations, in which morphologically complex forms have no independent representations, and the recent position of Bybee (1988), in which all forms are highly associated with one another and form complex networks with membership in particular schemas.

The assumption that plural formation in children is influenced by schemas is not entirely new. Berko herself mentions the idea at various points in her I 958 article, as do Anisfeld \& Tucker (1967), but does not develop it. Berko (1958: r64) mentions occasionally for example that her subjects repeated the stem as if it were already in the plural and she goes on to suggest that the child's rule for the formation of the plural seems to be 'a final sibilant makes a word plural'. Furthermore, MacWhinney (I978) seems to have this idea in mind when he remarks that German-speaking children tend to omit plural marking when a given noun in its citation form sounds plural; e.g. Hammer 'hammer' or Pfeife 'pipe'. The word endings -er and -e are possible plural markers in German, e.g. das Kind-die Kinder 'child-children' or der Tisch-die Tische 'table-tables' (cf. Table 5 for further information on the German plural marking system). MacWhinney suggests that children apply an 'affix-checking' principle to the noun they retrieve from their lexicon. What this means is simply that the English plural morpheme $\{-z\}$ is omitted in cases where the nonce word already ends in $/ \mathrm{z} /$ or $/ \mathrm{s} /$, e.g. niz or tass respectively (cf. also Solomon (1972), Innes (1974), Derwing \& Baker (I979) and Baker \& Derwing (I982)). Furthermore, the children's behaviour in the Berko experiment seems to be compatible with observations Linell (1976), Stemberger (198I), Menn \& MacWhinney (1984), and Stemberger \& MacWhinney (i986) report, namely that many languages of the world avoid repetition of identical morph shapes. Menn \& MacWhinney (I984: 529) even propose a weak morphological universal which they term REPEATED MORPH CONSTRAINT, formally expressed as follows:

*XY, where $\mathrm{X}$ and $\mathrm{Y}$ are adjacent surface strings such that both could be interpreted as manifesting the same underlying morpheme through regular phonological rules, and where either

(a) $\mathrm{X}$ and $\mathrm{Y}$ are both affixes, or

(b) either $\mathrm{X}$ or $\mathrm{Y}$ is an affix, an the other is a (proper subpart of a) stem.

All this means is that for the child, and to a certain degree also for an adult (cf. Köpcke (I 988$)$ ) a prototypical singular noun would be one that does not have features of a plural schema. Particular features of singular nouns in English that could be interpreted as strongly plural-like are the stem-endings $/ \mathrm{s} /, / \mathrm{z} /$ and $/ \mathrm{rz} /$. But note that the most common plural morpheme $\{-\mathrm{z}\}$ appears as a stem-final segment in only a handful of cases in singular nouns, 
e.g. lens, whereas /s / is relatively frequent in singular nouns e.g. fox, and / Iz/ is extremely rare, e.g. kermes (a type of louse). Furthermore, /Iz/ is iconically suggestive of plurality when compared to $/ z /$ and $/ s /$, since it is an added syllable. These observations lead to hypothesis concerning the degree of similarity of the form of singular nouns to plural morphemes, and corresponding tendencies to reinterpret singular forms as plural. The hypotheses are based on an estimation of the perceptual characteristics of the given plural markers of the language, following psychological principles of categorization, as given in Smith \& Medin (I98I) and MacWhinney ( I989). Table 3 elaborates the hypotheses in terms of the SALIENCE, FREQUENCY, CUE

TABLE 3. Cue strength of plural markers in English

\begin{tabular}{ccccc}
\hline Marker & Salience & $\begin{array}{c}\text { (Type) } \\
\text { frequency }\end{array}$ & $\begin{array}{c}\text { Cue } \\
\text { validity }\end{array}$ & Iconicity \\
\hline$/-\mathrm{s} /$ & $\mathrm{h}$ & $\mathrm{m}$ & 1 & $\mathrm{~m}$ \\
$/-\mathrm{z} /$ & $\mathrm{h}$ & $\mathrm{h}$ & $\mathrm{m}$ & $\mathrm{m}$ \\
$/-\mathrm{Iz} /$ & $\mathrm{h}$ & $\mathrm{l}$ & $\mathrm{h}$ & $\mathrm{h}$ \\
\hline
\end{tabular}

VALIDITY ${ }^{2}$ and ICONICITY of the individual plural markers in English. Each parameter is divided into three levels: high $(\mathrm{h})$, mid $(\mathrm{m})$, and low (l). The term CUE STRENGTH will be used here to refer to the sum effect of these four factors on the functional strength of a particular plural marker. Note that this is a first approximation, it is a question of further research to weight the relative sub-strength of each of these factors.

SALIENCE is here understood as a rough estimation of the degree to which a marker is perceptually detectable by a listener, in other words, its acoustic prominence. In the sense of Slobin's ( I 973) operating principles, all English plural markers are relatively salient, because they are separable segments in comparison with the corresponding contrast form, i.e. the singular form of a noun, and all of them are suffixes.

TYPE FREQUENCY here refers to the number of nouns that take a particular plural morpheme. The most frequent morpheme is $\{-z\}$, less frequent is $\{-\mathrm{s}\}$, and the least frequent is $\{\mathbf{I Z}\}$.

CUE VALIDITY is used in its restricted sense as the complement of frequency, i.e. the frequency with which a particular feature occurs in the category which contrasts with the target category. In the context of English plural morphology, $\{-z\}$ has medium and $\{-I z\}$ has high cue validity, because there are only a few singular nouns that end in $/-z /$ and nearly none that end in

[2] MacWhinney, Pleh \& Bates ( 1985 ) introduce the terms Detectability, availability and RELIABILITY for SALIENCE, FREQUENCY and CUE VALIDITY, respectively. Here, I have continued to use the older terms since at the point of writing they seem to be more established in the psychological literature.

300 
/-Iz/. The remaining morpheme $\{-\mathrm{s}\}$ has relatively low cue validity, because there are relatively many singular nouns in English that end in /-s/, e.g. box/bãks/.

Finally, the principle of ICONICITY suggests that additive morphemes, especially syllabic ones, are evocative of plurality (more in the signal $=$ more in the referent). On this basis $\{-I Z\}$ is most evocative of plurality among the English plural allomorphs.

Of the four criteria for determining the cue strength of plural markers in English, $\{-Z\}$ and $\{-I Z\}$ rank higher than $\{-\mathrm{s}\}$. From there, I hypothesize then that $\{-z\}$ and $\{-I z\}$ are 'better' plural markers than $\{-s\}$. From this it follows, in the context of a theory of cue strength, that in processing nonce words children should display some tendency to interpret intended singular forms ending in $/ \mathrm{s} /, / \mathrm{z} /$, and $/ \mathrm{Iz} /$ as acceptable plurals, and to therefore leave them unchanged in an experimental task requiring them to form plurals. Furthermore, they should tend to do so more with / $\mathrm{z} /$ and / Iz/ than with /s/. This line of reasoning on cue strength can be extended. Stem-final segments which are similar to but not identical with plural allomorphs should show a slight tendency to be taken as plurals in a nonce task, a tendency which should reduce or disappear as the final segment of the nonce word stimuli becomes more dissimilar to actual plural allomorphs. These considerations lead to a rank ordering of Berko's stimuli as presented in Fig. 2.

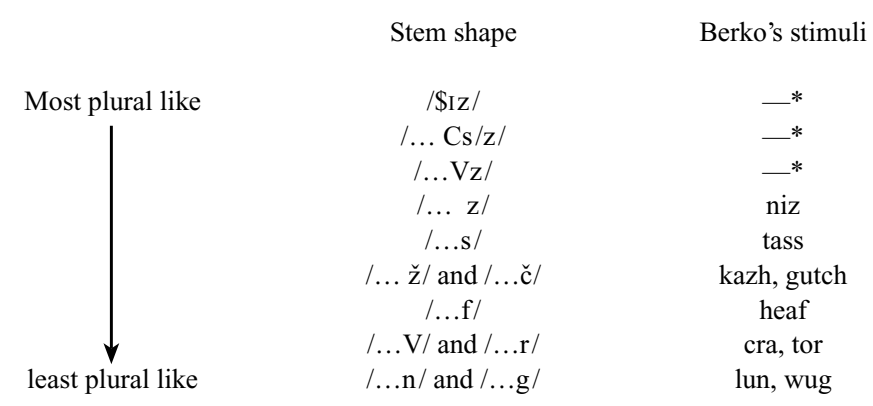

*Berko did not test these stem shapes, but they are of theoretical interest; example stimuli would be /pučIz, /pãks/, and /riz/.

Fig. 2. Rank ordering of Berko's data based on perceptual distance from actual plurals.

Skipping the first three items, stem-final $/ z /$ is identical to the plural allomorph with the highest cue strength, as discussed above. ${ }^{3} \mathrm{Next}, / \mathrm{s} /$ is identical to the plural allomorph with lower cue strength. For the ranking of the other stem endings the following articulatory features are important: continuancy, friction, and sibilancy. The palatal sibilants $/ \breve{z} /$ and $/ \breve{c} /$ are

[3] Berko's experiment did not contain nonce word stimuli with final / $\mathrm{Iz} /$. 
non-identical but phonetically highly similar to the regular plural allomorphs of English. They are characterized by exactly these three features. ${ }^{4}$ The fricative /f/ is still more removed from the regular plural allomorphs: it satisfies the features [+ continuant] and [ + fricative], but it is [-sibilant]. The vowel and the liquid $/ \mathrm{r} /$ are both continuant but are negatively specified with regard to friction and sibilancy. Finally, $/ \mathrm{n} /$ and $/ \mathrm{g} /$ can be grouped together, since they are negatively specified for all three features.

Figure 3 represents a reanalysis of zero responses of the six/seven-yearolds in Berko's data. Roughly, the curve shows a clear correspondence between the degree of resemblance to canonical plurals and the extent to

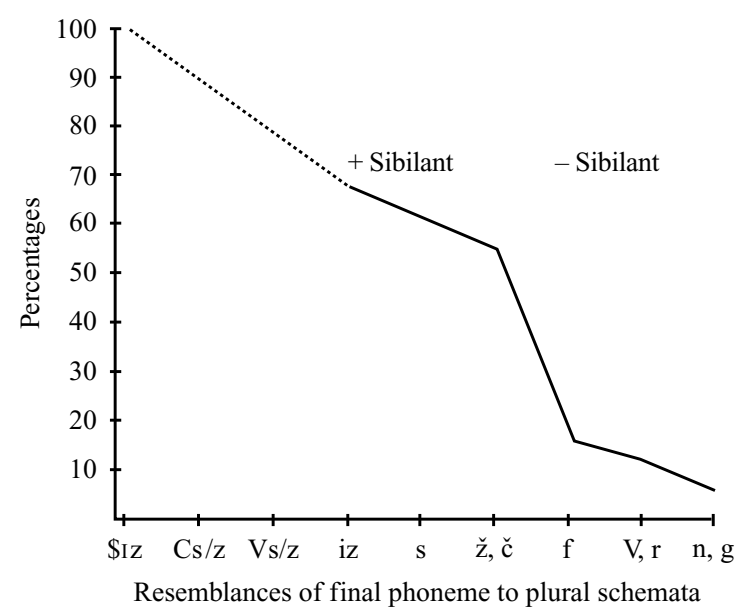

Fig. 3. Zero responses in percentage of the six/seven-year-olds (based on Table 2) according to resemblances of the final phoneme of the test items to plural schemata in English.

which Berko's six/seven-year-old subjects left the stimulus unchanged. This shows that the degree of perceptual similarity to a canonical plural may have affected their responses, and suggests that at some level of their response behaviour they perceived some forms as being more plural-like than others in accordance with the cue strength hypothesis.

One could argue, in support of the IP rule hypothesis, that there are two plateaus in the curve, one for stimuli ending in sibilants and the other for stimuli ending in non-sibilants, corresponding to the phonemic conditioning environments for the plural allomorphs $\{\mathrm{I} z\}$ and $\{\mathrm{s} ; \mathrm{z}\}$, respectively. This plateau effect certainly shows that incomplete acquisition of the plural

[4] The description of the affricate / $\check{c} /$ as a fricative continuant is motivated by the fact that the second part of the phoneme produces audible friction. 
allomorph $\{\mathrm{Iz}\}$ plays a role in the subjects' behaviour. However, arguing for plateaus fails to account for the consistent drop in the curve from $/ z /$ to $/ \breve{z}$, $\breve{c} /$, and the consistent drop from /f/ to /n, g/. If perceptual distance from canonical plurals had no effect, then the shape in these plateaus would have been absent. Admittedly, the number of data points is small, but the line of reasoning given is supported by findings from Innes ( I 974) (cf. the following section).

The three hypothetical points on the curve represent theoretical pivotal predictions about stimuli that Berko did not test. The cue strength hypothesis predicts that a factor complementary to the perceptual distance from canonical plurals will play a role. This is the perceptual distance of the stem from canonical singular forms once the putative plural morpheme has been segmented (cf. Köpcke ( I 988)). Thus, although the final segments of $n i z$ and tass are identical to canonical plurals, when they are segmented, the resulting stems /nI/ and / tæ/ are phonotactically impossible forms in English, and thus maximally distant from canonical singulars. A form such as / riz/ should be more likely interpreted as a plural, since the segmented stem / ri/ is phonotactically possible, although such vowel-final forms have low frequency. A form such as /pãks/ should be even more susceptible to a plural interpretation, since the segmented stem /pãk/ is a high frequency type for monosyllabic singular nouns. Finally, a form like / pučız/ should virtually force a plural interpretation since /-Iz/ has near zero frequency in singular forms, and /puč/ is a canonical singular.

In sum, the results of Berko's experiment do support her conclusion that children learn IP rules for plural formation in English, and, specifically, that the low frequency, phonotactically most restricted allomorph $\{\mathrm{IZ}\}$ is acquired after the others. But they also point to a learning mechanism in which canonical forms for both singular and plural lexical items are represented, and in which particular words are interpreted as singular or plural depending on their perceptual proximity to or distance from canonical schemata for singular and plural forms, respectively. This mechanism will be referred to as SCHEMA-LEARNING.

THE BAKER \& DERWING DATA

One problem with the Berko data is that the argument is based on a very limited data set. Fortunately, a far more extensive data set is available that puts the model to a more stringent test. From Innes's ( I 974) data set from I 20 children (20 at each age from 2 to 7 ) and 24 nonce stem-types Baker $\&$ Derwing ( I 982) yield a much more reliable picture of developmental stages children go through when acquiring the English plural morphology. Since the correlation in performance between the subjects in Innes's study and those in Berko's is very high $(r=0.96)$ on comparable stimuli for comparable 
SCHEMATA VERSUS RULES IN PLURAL MARKING

ages, there is good reason to believe that the reliability between the two studies is quite high. The main advantage of the more recent data set is that it can provide many more test points against which to compare the predictions of the model developed so far.

\section{Method and results}

Innes ( I 974) employed a similar version of the Berko technique to elicit her data. The responses to her 24 items by 120 children were first analysed in terms of the usual per cent correct according to age groups. Almost $97 \%$ of the total number of responses were one of the three regular plural allomorphs or zero. A grouping along the lines of correctness and mean age did not reveal very much, except that the children first acquire $/ z /$, then $/ \mathrm{s} /$, and last $/ \mathrm{Iz} /$ as plural markers.

In their reanalysis of the Innes data Baker \& Derwing ( 1982) grouped the children by focusing on response profiles. Instead of grouping children by age, those children with an identical or comparable response profile ("response coincidence matrix') were grouped together. In other words, age was not treated as the relevant factor for the analysis, but rather clusters of test items that were treated the same way. On that basis Baker \& Derwing divided the total number of subjects into six groups, eliminating two groups from further analysis on the basis of an inclusion criterion specifying that a subject had to leave at least three items and no more than $2 \mathrm{I}$ items in conformity with the adult pattern. On the lower end then one group of 8 subjects and on the higher end one of 18 subjects were excluded. Contrary to Baker \& Derwing I do not eliminate the group on the higher end ( 8 children), since, even for this group, the reanalysis of the results in light of the schema approach is quite interesting and fits into the theoretical picture.

\section{A reanalysis of Baker's and Derwing's results}

In what follows, I focus on the zero responses in order to establish the reliability of the interpretation of the Berko data. Groups I and II in the Baker \& Derwing analysis I will treat as one group for several reasons, the main one being that group II contains only 7 subjects, which leads to the assumption that the percentages given might be not very reliable. Furthermore, with regard to the zero responses, which are at issue here, both groups behave fairly identically; and third, the mean age between both groups is very close.

In the following Table 4 the zero responses within the 4 groups are given as a function of the final phoneme of the stimuli. Again, as with the interpretation of the Berko data, phonemes are grouped together on the basis of shared phonetic features. Figure 4 projects the results given in Table 4 
TA В LE 4. Distribution of zero responses in percentages to 24 nonce words grouped according to resemblance of the final phoneme

\begin{tabular}{|c|c|c|c|c|c|c|c|c|c|}
\hline Group & $\begin{array}{l}\text { Mean } \\
\text { age }\end{array}$ & z & $\mathrm{s}$ & $\begin{array}{l}\check{z}, \check{s}, \\
\check{c}, \mathrm{~d} z\end{array}$ & $\begin{array}{l}v, f, \\
\partial, t\end{array}$ & ว, i, u & $\mathrm{r}, 1$ & $\mathrm{n}, \mathrm{n}, \mathrm{m}$ & $\begin{array}{c}\mathrm{B}, \mathrm{D} \\
\mathrm{G}^{*}\end{array}$ \\
\hline $\mathrm{II} \uparrow$ & $4 \cdot$ I I & 95 & 90 & 94 & 63 & 48 & 48 & 58 & 54 \\
\hline III & $4 \cdot 22$ & 94 & 70 & 68 & 32 & 2 & 4 & $<\mathrm{I}$ & 4 \\
\hline IV & 4.92 & 92 & 68 & 54 & 2 & 8 & 0 & ० & 3 \\
\hline $\mathrm{V}$ & $5 \cdot 78$ & 33 & 22 & 4 & o & ० & $\circ$ & ० & o \\
\hline
\end{tabular}

* 'B', 'D' and ' $G$ ' refer to the phenomes $/ \mathrm{b}, \mathrm{p} /, \mathrm{d}, \mathrm{t} /$ and $/ \mathrm{g}, \mathrm{k} /$, respectively.

$\uparrow$ Group II here is group I and II in Baker \& Derwing (I982).

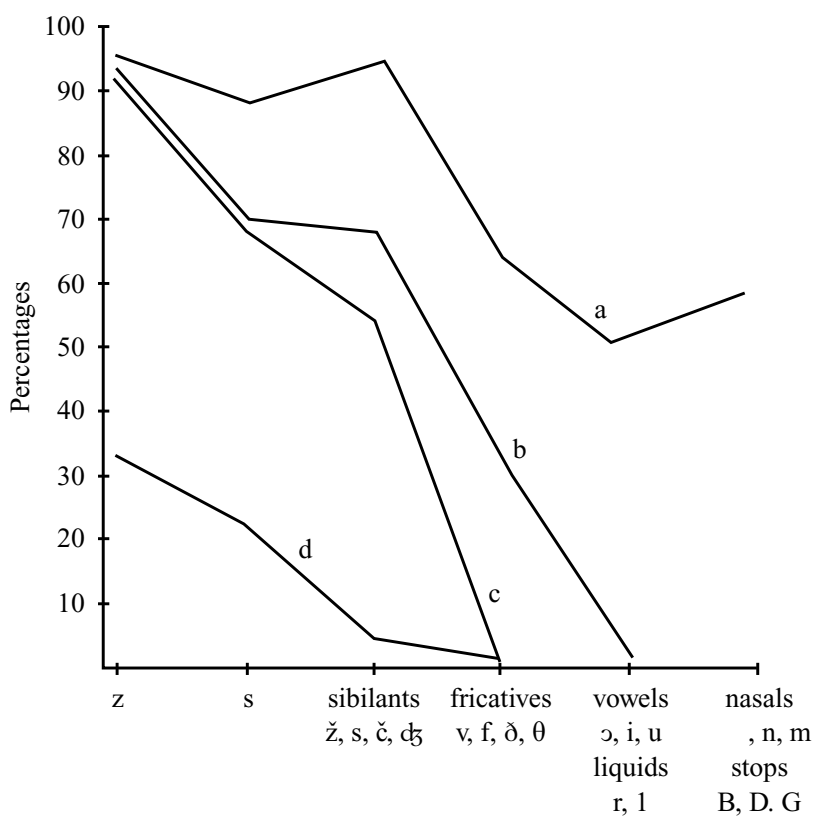

Resemblances of final phoneme to plural schemata

Fig. 4. Distribution of zero responses in percentages according to resemblances of the final phoneme of the test items to plural schemata in English (line ' $a$ ' refers to group II, ' $b$ ' to group III, 'c' to group IV, and 'd' to group V).

onto a scale of decreasing similarity of final phonemes to plural schemata. Figure 4 reveals the following: the youngest children seem to have no knowledge of a productive pluralization rule, but they obviously make a distinction between sibilants and, to a certain extent, also fricatives on the one hand and other word endings on the other hand. Sibilants and fricatives share phonetic features with the actual plural markers in English. The more 
one approaches the prototypical plural marker, the more the children leave the word unchanged, i.e. assign $-\emptyset$.

The children belonging to group III still assign - $\emptyset$ to fricatives and sibilants, but they do this to a lesser extent than the children in group II. Furthermore, they clearly do not confuse vowels, liquids, nasals, and stops in word final position with potential plural endings anymore.

The main difference between group III and IV is that the children belonging to group IV do not treat non-sibilant fricatives as potential plural endings anymore. But they obviously still treat a nonce word ending in $/ \mathrm{z} /$ or $/ \mathrm{s} /$ or in $/ \breve{z}, \breve{s}, \breve{c}, d z /$ in the majority of the cases as being already plural. Over all endings they do slightly better than the children in group III, since there is not a single crossing of the curves.

The oldest children (group V) perform best. They do master siblilants, but, surprisingly, they do not do so in all cases with $/ \mathrm{z} /$ and $/ \mathrm{s} /$. Again, the more one approaches the prototypical plural ending, the more likely it is that the children leave the word unchanged, i.e. from about one fifth for $/ \mathrm{s} / \mathrm{up}$ to about one third for $/ \mathrm{z} /$.

Overall then, we get impressive independent support from the Innes ( 1974) data for our interpretation of the Berko data. But one should keep in mind that in English, plural formation is not an ideal domain in which to study this mechanism of building up schemata for assigning grammatical functions to forms since the distribution of allomorphs in the lexicon strongly invites an IP rule-based learning mechanism. In contrast, German plural formation, as shown by Köpcke (1988, I 993), suggests a schema-learning interpretation in the distribution of forms in the lexicon, an interpretation supported both by the behaviour of adult subjects in a nonce word task, and also by historical change. Before elaborating the schema-learning hypothesis more closely I will therefore turn to the organization of the German system and to experimental results with children.

\section{The acquisition of plural marking in German}

Plural marking in German differs from English considerably, since it is a complex system composed of several phonologically unrelated alternants and no clearly dominant rule. German has six major plural allomorphs, the occurrence of which correlates with at least the morphological factors given under (2):

(2) morphological factor - the type of the derivational suffix

- the final consonant or vowel of the stem

- the prefix of the stem noun examples

Frei-heit +-en 'freedoms', Jüng-ling $+-e$ 'young men' Pizza $+-s$ 'pizzas', Kurve $+-n$ 'curves' Ge-birg-e+- 'mountains’ 


\section{KLAUS-MICHAEL KÖPCKE}

- the mutability of the stem noun ${ }^{5}$ Vater/Väter 'fathers'

- the gender-assignment of der Tisch/die -e 'tables', the noun $^{6}$ die Uhr/die___en 'watches' das $\mathrm{Kind} / \mathrm{die}$ -er 'children'

- the animacy of masculine der Herr/die -en 'sirs' nouns

The fact that none of these patterns dominates is apparent in Mugdan's ( I977) detailed description of plural marking in German: he attempted to set up IP rules for this complex system and ended up with I 5 distinct rules and $2 \mathrm{I}$ lists of exceptions. Table 5 presents the plural morphemes in more detail.

TABLE 5 Overview of native nominative plural morphemes in German

\begin{tabular}{|c|c|c|c|}
\hline Plural morpheme & Masculine & Feminine & Neuter \\
\hline$-\mathrm{e}$ & Fisch/Fische (fish) & $\begin{array}{l}\text { Kenntnis/-nisse } \\
\text { (knowledge) }\end{array}$ & Jahr/Jahre (year) \\
\hline$-(e) n$ & $\begin{array}{l}\text { Bauer/Bauern } \\
\text { (farmer) }\end{array}$ & Tür/Türen (door) & Auge/Augen (eye) \\
\hline -er & $\begin{array}{l}\text { Geist/Geister } \\
\text { (ghost) }\end{array}$ & - & Kind/Kinder (child) \\
\hline$-\mathrm{s}$ & Park/Parks (park) & $\begin{array}{l}\text { Mutti/Muttis } \\
\text { (mom) }\end{array}$ & Auto/Autos (car) \\
\hline$-\emptyset$ & Adler/Adler (eagle) & - & $\begin{array}{l}\text { Fenster/Fenster } \\
\text { (window) }\end{array}$ \\
\hline Umlaut & Vater/Väter (father) & $-*$ & $-\uparrow$ \\
\hline Uml. +-e & Sohn/Söhne (son) & Kuh/Kühe (cow) & $-f$ \\
\hline Uml. + -er & $\begin{array}{l}\text { Wald/Wälder } \\
\text { (wood) }\end{array}$ & - & $\begin{array}{l}\text { Volk/Völker } \\
\text { (people) }\end{array}$ \\
\hline def. article & $\begin{array}{l}\text { der SING/die } \\
\text { PLURAL }\end{array}$ & $\begin{array}{l}\text { die SING/die } \\
\text { PLURAL }\end{array}$ & $\begin{array}{l}\text { das SING/die } \\
\text { PLURAL }\end{array}$ \\
\hline
\end{tabular}

* In the entire lexicon there are only two instances, namely Mutter-Mütter 'mothermothers' and Tochter - Töchter 'daughter - daughters'.

$\uparrow$ Only one instance, namely Kloster - Klöster 'monastary - monastaries'

† Only one instance, namely $F l o \beta-F l o ̈ \beta e$ 'raft - rafts'.

The first four are suffixes; the fifth is phonetically zero, and is analysed as a zero morpheme, since it occurs in plural contexts completely parallel to the other plural suffixes. The sixth is an 'umlaut' mutation in the stem vowel of the singular form of the word, for example the change from $[\mathrm{u}]$ to $[\mathrm{y}]$ in Bruder-Brüder 'brother - brothers'. Umlaut is the only morpheme which

[5] The morphologization of the vowel harmony process in Old High German known as 'Umlaut' has led to vowel alternations which enter into a number of morphological paradigms. In Modern Standard German (spoken) the vowels $/ \mathrm{a} /, \mathrm{o} / \mathrm{,} / \mathrm{u} /$, and $/ \mathrm{ow} /$ have alternants, while /i/, /e/, and /ai/ do not. The former will be referred to here as MUTABLE ('umlautfähig').

[6] The factor 'gender-assignment' is probably the most important one for determining the plural marker (see Bittner ( 1994$)$ ). 
can combine with others, namely $-\emptyset,-e$ and $-e r$. Some of the morphemes are limited to two of the three gender classes. Thus while gender does not predict the plural morpheme, it does limit the choice. Although determiners are not viewed in structural analyses as plural markers, they will be included in the present analysis, since, from a perceptual point of view, they are an additional source of information in the NP about number, and when they co-occur with the zero suffix, they are the only source of information. When masculine nouns are marked for plural, the article in the nominative case changes from der to die, and for neuter nouns from das to die. From this perceptual perspective it is clear why zero is never used as a plural suffix morpheme for feminine nouns: in this case the singular and plural articles are identical, both die, so that some other overt marker is needed. In what follows, we restrict ourselves to the definite article in the nominative case. One might object that the cue validity of the masculine singular nominative $d e r$ is reduced by the fact that it is homophonous with the genitive plural definite article in all genders. However, it has to be borne in mind that children (and many adults) usually use a periphrastic construction with the preposition von 'of' as a substitute for the genitive.

In Table 6 the cue strength of the German plural markers is evaluated. Again, as with the English plural markers it is a question for further research to weight the relative sub-strength of each of these factors. The German

TAB LE 6. Cue strength of plural markers in German

\begin{tabular}{llccc}
\hline Marker & Salience & $\begin{array}{c}\text { (Type) } \\
\text { frequency }\end{array}$ & $\begin{array}{c}\text { Cue } \\
\text { validity }\end{array}$ & Iconicity \\
\hline$-(\mathrm{e}) \mathrm{n}$ & $\mathrm{h}$ & $\mathrm{h}$ & $\mathrm{h}$ & $\mathrm{h}$ \\
$-\mathrm{s}$ & $\mathrm{h}$ & $\mathrm{l}$ & $\mathrm{h}$ & $\mathrm{m}$ \\
$-\mathrm{e}$ & $\mathrm{h}$ & $\mathrm{m}$ & $\mathrm{l}$ & $\mathrm{h}$ \\
$-\mathrm{er}$ & $\mathrm{h}$ & $\mathrm{l}$ & $\mathrm{l}$ & $\mathrm{h}$ \\
Umlaut & $\mathrm{l}$ & $\mathrm{l}$ & $\mathrm{m}$ & $\mathrm{l}$ \\
\hline
\end{tabular}

plural markers $-(e) n,-s,-e$, and -er can be characterized as salient for the same reason as for the English plural markers. In contrast, umlaut is neither a separate segment nor stem final and is thus less salient. The most frequent plural morpheme in German is $-(e) n$ followed by $-e$. In comparison, $-s,-e r$ and umlaut have low frequency. The plural marker $-(e) n$ has high cue validity, because there are relatively few singular nouns that end in /en/. ${ }^{7}$ The same holds for $-s$. In contrast, $-e$ has low cue validity as a plural marker, because there are many $-e$-stem nouns, most of which are feminine. Low cue validity

[7] Nominalization of verbs, e.g. laufen $>$ das Laufen 'to run $>$ running', do not count, because these nouns always have a verbal partner, consequently, the nouns always encode a course of events 
has to be assigned to -er, since many singular nouns end in /er/. In fact, -er is a productive derivational suffix for agentive nouns just as it is in English. Finally, the situation with umlaut is complex: some low-frequency umlauted vowels have moderate cue validity as plural markers, whereas the high frequency vowel 'ä' $(=/ \varepsilon /)$ does not. In sum, umlaut has mid cue validity as a plural marker. Iconicity holds for all German plural markers except umlaut, although $-s$ is less iconic than $-(e) n,-e$ and $-e r$, since the application of $-s$ never results in a new syllable, whereas the application of the other three plural morphemes frequently does result in a new syllable.

I hypothesize then that plural marking is output (product) oriented (cf. Zager (I980), Stemberger \& MacWhinney (1986)). Consequently, speakers form the plural of a noun by matching it to one (or more) abstract plural schemas residing in the mental lexicon, rather than by blindly generating the plural form with an IP rule applied to the (input) form. Furthermore, speakers must have schematic singular representations, with individual schemas differing in cue strength for singularity and plurality, producing the continuum ranging from prototypical singular to prototypical plural as shown in Fig. 5 (cf. Köpcke ( I 988, I 993) for a more detailed discussion of

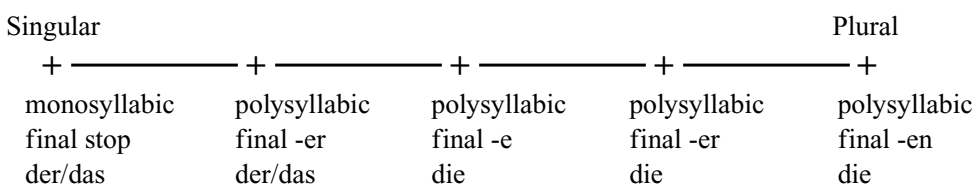

Fig. 5. Continuum for plural schemas in German.

this continuum). Masculine and neuter monosyllabic forms have maximal cue strength for singularity, since monosyllabic stems have high frequency among singulars, and virtually zero frequency among plurals. A mid-point on the scale is provided by polysyllabic forms with final schwa and the article die, such as die Tasse 'cup' and die Tische 'tables'; this particular schema has approximately equal cue strength for both singular and plural. Anchoring the other end of the scale are polysyllabic forms ending in /-an/ and occurring with the article die. These forms have very high frequency among plurals, and virtually zero frequency among singulars. ${ }^{8}$ The decision as to whether a particular form is singular or plural is thus based on the overall structure of the form in question, and not just on the presence or absence of markers. In

[8] A few still exist in southern dialects, such as die Plunzen 'a type of sausage.' Such singulars were gradually eliminated from the language in Middle High German as the cue strength of $\{\mathrm{en}\}$ for plural marking increased (see Köpcke (1988, I993)). 
particular, the language user's decision concerning the singularity or plurality of a particular form (X) is, then, based on two factors:

(i) Position on the continuum of the schema to which the form (X) conforms.

(ii) The existence of a (concept-identical) lexical partner (Y) conforming to a schema situated to the right or to the left of $(\mathrm{X})$ on the continuum.

The first factor suggests that a particular schema has an absolute cue strength for signalling singular or plural, while the second suggests that it has a cue strength relative to other schemas on the continuum. In the case of nonce words I assume that mainly factor (i) will be of importance, since no lexical partner exists in the child's lexicon. In other words, then, I hypothesize that the child would tend to treat a given nonce word as being plural the more to the right on the continuum the form is, i.e. the more it matches a plural schema and correspondingly less a singular schema.

MUGDAN'S DATA

Method and results

Mugdan's (1977) nonce word task with 25 German six/seven-year-old preschoolers and first graders (Mugdan does not give the mean age of his subjects) followed exactly the design of Berko's study. Table 7 gives the

TABLE 7. Distribution of responses of 25 children to 16 German nonce words in absolute numbers

\begin{tabular}{|c|c|c|c|c|c|c|c|}
\hline Stimuli & $\begin{array}{l}\text { Expected plural } \\
\text { morpheme }\end{array}$ & $-\emptyset$ & $-e$ & $-(\mathrm{e}) \mathrm{n}$ & -er & $-s$ & Noeologism \\
\hline der/šmirl/ & $-e /-(e) n$ & I 3 & 9 & - & I & - & 2 \\
\hline das/getrydə/ & $-\emptyset$ & 24 & - & I & - & - & - \\
\hline die/albər/ & $-(\mathrm{e}) \mathrm{n}$ & 23 & - & I & - & I & - \\
\hline das / tinda/ & $-(\mathrm{e}) \mathrm{n}$ & 23 & I & - & - & I & - \\
\hline die/za:ri/ & $-s$ & I 8 & - & I & - & 5 & I \\
\hline das /gelek/ & $-\mathrm{e}$ & I 8 & 7 & - & - & 一 & - \\
\hline der /n $\varepsilon$ : bər/ & $-\emptyset$ & 25 & - & - & - & 一 & - \\
\hline die /rondatš/ & $-(\mathrm{e}) \mathrm{n}$ & 22 & 3 & - & - & - & - \\
\hline das /bros/ & -e/-er & I7 & $8 / 3^{*}$ & - & - & - & - \\
\hline die /arl/ & $-e /-(e) n$ & I9 & 5 & - & - & I & - \\
\hline der/ha:gən/ & $-\emptyset$ & 25 & - & - & - & - & - \\
\hline die /ne:bə/ & $-(\mathrm{e}) \mathrm{n}$ & I7 & - & 7 & 一 & 一 & I \\
\hline das /heklain/ & $-\emptyset$ & $2 \mathrm{I}$ & 3 & - & - & I & - \\
\hline $\operatorname{der} /$ fendə/ & $-(\mathrm{e}) \mathrm{n}$ & 24 & - & I & - & 一 & - \\
\hline das /kundər/ & $-\emptyset$ & 25 & - & - & - & - & - \\
\hline der /farst/ & $-e$ & 22 & I & 2 & - & - & - \\
\hline
\end{tabular}

* In 3 out of 8 cases $-e$ was combined with umlaut. These are the only cases where the children made use of umlaut. This is in accordance with the predictions based on the cue strength of the German plural markers (see Table 6). 


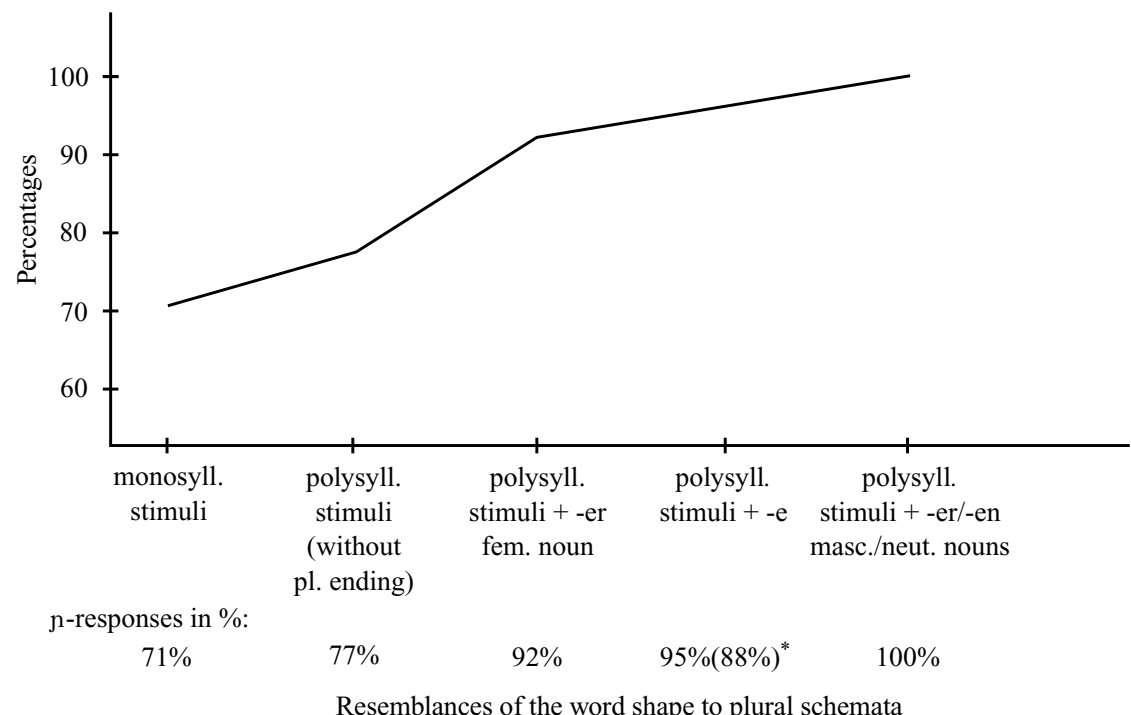

Fig. 6. Distribution of zero responses in percentages according to resemblances of the word shape to plural schemata in German.

* The percentage of $ø$-responses for pollysyllabic words ending in - $e$ goes down to $88 \%$ if the stimulus die/ne:bə/ is taken into consideration. But there are at least two problems involved with this stimulus, both of which lead to the decision to disregard it: (i) die/ne:bə/ has a partner in the real lexicon, namely neben 'next to'. The presence of such real partners to nonce words was identified as a strong determinant of response behaviour in Köpcke ( I 988); (ii) a stimulus like die/ne:bə/ is, because of its structure die [\#- e], very provocative for $n$ affixation, since there are literally thousands of feminine nouns ending in Schwa that take $-n$ as their plural marker. This is reflected in the children's responses (see Table 7).

results. ${ }^{9}$ The proportion of zero responses was at least 7 I per cent ranging up to Ioo per cent, suggesting considerable uncertainty in the nonce word task relative to Berko's English data. There was no difference in the behaviour between the older and the younger children. Mugdan (1977: I72) notes that the children's behaviour is not describable on the basis of simple morphological rules. He assumes that his subjects were looking for analogies by using the sound of the test items rather than determining a plural allomorph on the basis of gender assignment or a particular stem ending. The different proportion of zero responses, i.e. the repetition of the test item, is not a topic in Mugdan's analyses.

A reanalysis of Mugdan's results

Figure 6 projects the results given in Table 7 onto a scale determined by the cue strength hypothesis as detailed in Fig. 5. Figure 6 shows that the

[9] Six of Mugdan's stimuli were eliminated (/mada:t/, /šare:t/, /fore:t/, /gredõ/, /عrla:t/, and /kefi:/) because they represent the phonotactics of erudite French loans in German, which are not within the competence of six/seven-year-old children.

3 I I 
perception of forms as possible plurals may have played a role in the response behaviour. The prototypically singular monosyllabic stimuli received the lowest number of zero responses, approximately 70 per cent.

Polysyllabic stimuli ${ }^{10}$ received a slightly higher number of zero responses, corresponding to the slight increase in plural-likeness of the form, although these specific forms are not possible plurals in the real lexicon. This observation is in accordance with Anisfeld \& Tucker (1967: 1 207/08). They note that children tend to interpret longer forms, such as the nonce word bipum, as being plural.

Forms ending in $-e r$ and $-e$ are possible plurals, and receive a still higher number of zero responses. Finally, forms, ending in -er or -en, for which the normative plural is zero received roo percent zero responses. On first sight there seems to be a contradiction between the order of schemas in Figs 5 and 6. But, for the identical schema [polysyllabicity + -er] mentioned before, the normative plural is $-n$ since the stimulus is the feminine nonce word die/albər/.

Furthermore, it can be shown that the children were sensitive to the presence of the article die (feminine gender or plural) versus the articles der and das (masculine and neuter singular, respectively) as a component of plural and singular schemas. Monosyllabic der/das-items receive zero in $69 \%$ of the cases, whereas the number for items classed as die is $76 \%$. For polysyllabic items the numbers are 72 and $80 \%$, respectively. Here, only those items are counted, which do not have a particular ending $(-e,-e r$, and -en) that could be interpreted as a plural marker. Admittedly, the numbers are small, in fact, they are even too small to run a test for significance, but note that they all fit without a single exception the argument developed in this article.

In sum, the reinterpretation of Mugdan's results in light of the schema theory shows that the closer the stimuli approximated plural schemas with greater cue strength, the more German children were inclined to give zero responses.

\section{SPONTANEOUS DATA FROM GERMAN}

So far, the discussion has focused on the primary goal of this study: the reinterpretation of zero responses in the formation of plurals to nonce words. The schema-theoretic interpretation of zero responses in the Berko (I958), Innes (1974) and Mugdan (1977) experiments suggests that in acquiring plural morphology, children build schematic representations of possible singular and plural lexical items, and attempt to match their growing nominal

[ı。] The polysyllabic stimulus das /heklain/ was eliminated from consideration in Fig. 6 because it matches a real word in the lexicon, namely das Hecklein 'little hedge.' 
lexicon to these schemas. The effects of this show up clearly in Englishspeaking children's acquisition of plural lexical items, which is surprising at first sight, since plural allomorphs are phonemically conditioned, and therefore sorted by phonemic environments as stems are acquired. In German, plural allomorphs are not phonemically conditioned and are therefore much more subject to the schema-building process.

If German children are building schematic representations of possible plurals, then in their expanding lexicon they should show evidence of forms which match plural schemas, but are not the normative (adult) plural of corresponding singular nouns. Veit (i 986) provides ample evidence of this type in a Berko-style elicitation of plurals to real nouns, all of which were within the productive vocabulary range of the six-year-old subjects. About 90 per cent of the childrens' responses were the expected target form. Of the other io per cent, less than 2 per cent were zero responses, and virtually all the rest were deviant forms that matched plural schemata. In these deviant responses the children made use of all the plural allomorphs (cf. Table 5). Some examples are given under (3):

(3) normative plural Elefanten 'elephants' Ärzte 'doctors' Bälle 'balls' Messer 'knives' deviant plural

Elefänte

Ärzten

Bäller

Messers

Furthermore, Veit elicited the same words from the children twice. In nine cases the same deviant form was used twice. But in four cases different deviant forms were used in the two trials. This indicates that even with familiar nouns, the children were actively applying plural schemata, but were not sure which schema to apply to a particular noun. Finally, there were a small number of cases of double marking, e.g. Kleid-er-s 'clothing', Indianer$n-s$ 'Indians'. In these cases the singly marked plural may not have been perceived as sufficiently plural-like, and so the second marking was added to achieve an unequivocally plural form for the child (cf. the historical double marking of child-r-en in English). There are two points in Veit's data I will discuss in more detail, supported by spontaneous tape-recorded data gathered from my daughter Pauline at age 3; 0 in play situations. One might argue at this point that the two data sets are from different acquisitional phases; nevertheless, the strategies are strikingly similar and support the theoretical framework developed in this paper.

First, Veit noticed that children overgeneralize the form Umlaut $+-e$. She cites Elefänte (normative plural Elefanten). As a matter of fact, lots of cases of this kind can be found in Pauline's speech, e.g. die Pünkte 'points' 
(normative plural die Punkte), die Büsse 'buses' (normative plural die Busse), die Böte 'boats' (normative plural die Boote), etc. The interesting point in light of the schema theory is that in all of these cases the normative plural form matches a plural template, which is not very reliable for the expression of the function of plural in German (cf. Fig. 5). The schema [die + \# e] only represents the middleground of the continuum for plural schemas in German. The low cue strength of the plural schema based on $-e$ is particularly salient in the fact that many children add umlaut for plural forms based on the $e$-schema. Second, Veit noticed overgeneralization of $-s$ and $-(e) n$. Again, this can be confirmed on the basis of spontaneous data from my daughter. Most masculine and neuter nouns ending in -er or -el form their normative plural with $-\emptyset$, e.g. das Fenster-die Fenster. but, the schema [die +\#__-er/-el] is not very reliable for the expression of plural, since many feminine nouns resemble the same schema in their singular, e.g. die Kammer 'chamber' or die Amsel 'blackbird'. It is not surprising, then, that children overgeneralize plural markers in order to achieve a distinctive plural form. Particularly eligible for overgeneralization are plural markers with high cue strength, i.e. $-s$ and $-(e) n$. However, it is important to note that $-s$ does not show up in all contexts, although it has the least restrictions of all plural markers in German (cf. Bornschein \& Butt (1987)). Particularly interesting is the distribution of $-s$ and $-(e) n$, when the noun ends in a pseudosuffix, i.e. $-e r,-e l$ and $-e n,{ }^{11}$ and when the normative plural marker is $-\emptyset$. In Pauline's utterances (recorded over a period of two days) I found the following examples.

Table 8 shows that $-s$ and $-(e) n$ are not applied blindly. Both plural markers are applied whenever the schema is not very reliable for marking plural, i.e.

TABLE 8. The assignment of the German plural markers $-s$ and $-(e) n$ to pseudo-suffixed nouns in -er, -el, and -en by one child over a period of two days

\begin{tabular}{cccccc}
\hline [\#_er-s] & {$[\#$ _el-s] } & [\#_en-s] & [\#_el-n] & [\#_el-n] & [\#_en-en] \\
\hline die Ritters & die Zettels & - & die Räubern & die Schlüsseln & - \\
'knights' & 'paper slips' & & 'robber' & 'keys' & \\
die Fensters & die Schlüssels & - & die Mardern & die Zetteln & - \\
'windows' & 'keys' & & 'martens' & 'paper slips' & \\
die Räubers & die Esels & - & die Brudern & die Stengeln & - \\
'robber' & 'donkeys' & & 'brothers' & 'stems' & \\
\hline
\end{tabular}

[II] The term 'pseudo-suffix' refers to the frequently occurring but nonsegmentable endings $-e l$, -er, and -en. For example, -er is a suffix in Maler 'painter,' since the verb partner malen 'to paint' with the stem mal exists. Cases like Marder and Bruder look as if -er is segmentable, but a partner *Mard or *Brud does not exist. 
word endings in -er or $-e l .{ }^{12}$ Note that in some cases the same noun shows up with $-s$ and -en, e.g. Zettel. On the other hand, however, I did not find a single case, where $-s$ or $-e n$ were applied to a noun ending in the pseudo-suffix -en; for example, for der Wagen forms like *die Wagens or *de Wagenen did not occur. This distribution is compatible with the theoretical approach developed in this article since a noun ending in -en resembles a template that has high cue strength for marking plural in German. In exactly those cases the child left the nouns unchanged. These observations strongly support the schema theory and at the same time they are counter-evidence for the assumption of $-s$ being the default plural marker in German (cf. Clahsen et al. (1992) and Marcus et al. (1995)).

Finally, I will discuss longitudinal data on natural $\mathrm{L}_{\mathrm{I}}$ acquisition. The data were obtained by Harald Clahsen and his collaborators. ${ }^{13}$ Table 9 shows all deviant plural marking of 7 monolingual German children at around age 2; 6 during 5 to I 5 recording sessions. Each recording contains between 200

TA B LE 9. Deviant plural marking in natural LI acquisition

\begin{tabular}{|c|c|c|c|c|c|c|c|c|c|}
\hline & $\begin{array}{l}\text { No. of recordings } \\
\text { and age }\end{array}$ & $\begin{array}{l}(\mathrm{U})+ \\
\text {-en }\end{array}$ & $\begin{array}{c}(\mathrm{U})+ \\
-\phi\end{array}$ & $-\mathrm{e}$ & $-s$ & -er-n & -er-s & $\begin{array}{l}\text { Reduced } \\
\text { stem }\end{array}$ & Others \\
\hline Antje & 8 rec.; $2 ; 3^{-2} ; 9$ & I & 5 & 3 & I & I & - & I & - \\
\hline Annelie & 6 rec.; $2 ; 4-2 ; 9$ & - & 6 & I & - & - & - & - & - \\
\hline Inga & 7 rec.; $2 ; 4^{-2} ; 9$ & 8 & I & - & - & 2 & I & - & I \\
\hline Katrin & I 5 rec.; $2 ; \mathrm{I}-2 ; 6$ & 3 & 6 & I & I & - & - & I & I \\
\hline Marlis & 7 rec.; $2 ; 4-2 ;$ Io & - & I & - & - & - & - & 4 & - \\
\hline Sabrina & 6 rec.; I ; I I-2;2 & - & - & I & - & - & - & - & - \\
\hline Verena & 5 rec. $; 2 ; 4-2 ; 8$ & 3 & 2 & I & - & I & - & - & - \\
\hline$\Sigma$ & & I 5 & $2 \mathrm{I}$ & 7 & 2 & 4 & I & 6 & 2 \\
\hline
\end{tabular}

and 600 utterances. In addition to what Table 9 reveals it must be noted that the children produced only a very small number of deviant plural forms in actual speech. A rough estimate is that the children produce only approximately 2 to $3 \%$ deviant plural forms at that age. This is compatible with Marcus et al.'s (I992) finding that overregularization of the regular verb pattern takes place only in a small minority of cases, approximately $2.5 \%$. Probably at age 3; 0 and younger most of the forms are still learned by rote; a productive pattern of any kind of plural formation does not seem to be established yet, due to the relatively small number of nouns in the active vocabulary of the child. The establishment of other learning mechanisms

[12] Note that $-e l$ is not a possible plural marker in German and that $-e r$ is one, but with very low cue strength (see Table 6).

[13] Here, I would like to thank Harald Clahsen for providing the transcripts of 7 children aged $\mathrm{I} ; 5$ to $4 ; 0$. 
might be viewed as a function of the expanding lexicon. Taking this into consideration, Table 9 clearly shows that $-\phi$ and $-(e) n$ are overgeneralized, less so $-e$, and only in two cases $-s$. These findings are reliable, since compatible observations were made by Gawlitzek-Maiwald (1994); the overgeneralization is also noticed by Park (1978) and Mills (1985). Again, these results are not in harmony with the assumption of $-s$ being the default plural marker in German (cf. Clahsen et al. (I992) and Marcus et al. (I995)). One wonders, of course, why $-s$ does not show up more frequently, since the schema theory also predicts its overgeneralization due to its cue strength. An explanation could be that the basis in the children's lexicon at around age $3 ; 0$ is too small to develop any kind of generalization for $-s$. In the child's lexicon are some high-frequency s-plural nouns, like Mama-s 'mom-s' and Papa-s 'dad-s', but those are most likely rote learned. Otherwise, in the adult lexicon $-s$ is of low type frequency according to a study by Janda (I990). Marcus et al. (I 995) show in their study that $-s$ is restricted to proper names and foreign sounding nouns. Furthermore, the $s$-plural is clearly favoured in nouns ending in a full vowel, but those are in most cases loanwords, which are usually not accessible to children at age 3 ; 0 .

A close look at the overgeneralization of $-\emptyset$ and $-e n$ shows that the children's behaviour was far from random. In about two thirds of the $\emptyset$-assignments either the singular form already matched a plural template, e.g. die Möhre 'carrot' matches the template [die \#_UL_e], or the unchanged noun was preceded by a numeral or a scalar particle, e.g. viele 'many' or einige 'some'. The plural marker -en was assigned I I out of I 5 times when the normative plural was $-e$. As has been pointed out above, $-e$ is not a very reliable plural marker. In fact, $-e$ is as good a marker of feminine singular as it is of plural.

Double marking, e.g. Bild-er-n 'pictures', was only observed in cases where the normative plural was -er. In these cases, the singly marked plural may not have been perceived as sufficiently plural-like, and so the second marking was added to achieve an unequivocally plural form for the child. In 4 out 5 cases $-n$ is used as a second marker and in only one case $-s$. Under the assumption of a default one would have expected the opposite relation.

Finally, a word on reduced plural forms is due. A form such as die Vöge is counted as a reduced form, since the normative plural die Vögel 'birds' is shortened by some phonetic material, in this case the liquid /1/. Again, shortening does not occur arbitrarily. Table 9 mentions only 6 cases, but in all of these cases the reduction of the putative plural form leads to a better one. In all cases the shortening takes place with nouns ending in the pseudosuffix $-e l$. As previously indicated, most masculine and neuter nouns ending in $-e l$ form their plural with $-\emptyset$. This results in a very unreliable plural form. More reliable and more to the right of the continuum given in Fig. 5 would be a gestalt [die \#_Umlaut_e], resembled in a word like die Möhre 
'carrot'. It is exactly this schema which is matched in all 6 cases: normative die Vögel 'birds' or die Fußnägel 'toe-nails' > die Vöge and die Fußnäge.

\section{CONCLUSION}

The reanalysis of Berko (1958), Mugdan (I 977) and Baker \& Derwing (1982) suggests that their interpretation of zero responses has only partial validity. Children were clearly sensitive to the extent to which stimuli approximated high cue strength plural schemata, even when this was only a weak approximation (e.g. bi- versus monosyllabic stimuli). This observation is less remarkable with respect to Mugdan's data, since the behaviour of Germanspeaking adults in a nonce word experiment, the actual distribution of plural allomorphs in the German lexicon, and a substantial pattern of historical changes in German plural formation all point to a schema-learning model based on relative cue strength (cf. Köpcke (1988, I993)). It is worth mentioning, however, that the assumption of more or less reliable plural markers, where reliability is defined as a function of cue strength, is more capable of accounting for the data than the assumption of $-s$ being the default marker. In contrast, the observation is all the more remarkable with respect to the English data, since the phonemic conditioning of plural allomorphs in English, as well as the behaviour of English-speaking adults with nonce words, point so strongly to an IP model that English plural formation has become a frequently cited radical confirmation of IP rules as the basis of grammatical competence. The English data suggest that underlying the ultimate establishment of IP rules in the speaker's linguistic competence

there may be a schema-learning mechanism guiding the sorting out of singular and plural lexical forms, and the acquisition of plural morphology.

\section{REFERENCES}

Anisfeld, M. \& Tucker, G. R. (i967). English pluralization rules of six-year-old children. Child Development 38, $120 \mathrm{I}-\mathrm{I} 7$.

Baker, W. J. \& Derwing, B. L. ( 1982 ). Response coincidence analysis as evidence for language acquisition strategies. Applied Psycholinguistics 3, I93-221.

Berko, J. (I 958). The child's learning of English morphology. Word I4, I 50-77.

Bittner, D. (1994). Die Bedeutung der Genusklassifikation für die Organisation der deutschen Substantivflexion. In K. M. Köpcke (ed.), Funktionale Untersuchungen zur deutschen Nominal-und Verbalmorphologie. Tübingen: Niemeyer.

Bornschein, M. \& Butt, M. (1987). Zum Status des -s-Plurals im gegenwärtigen Deutsch. In W. Abraham \& R. Arthammar (ed.), Linguistik in Deutschland. Akten des $2 \mathrm{I}$ Linguistischen Kolloquiums, Groningen I 986. Tübingen: Niemeyer. I35-54.

Bybee, J. (1985). Morphology: a study of the relation between meaning and form. Amsterdam: Benjamins.

Bybee, J.(r 988). Morphology as lexical organization. In M. Hammond \& M. Noonen (eds). Theoretical Morphology. San Diego: Academic Press. I I9-4I.

Bybee, J. (I99I). Natural morphology: the organization of paradigms and language ac- 
quisition. In T. Huebner \& C. Ferguson (eds), Crosscurrents in Second Language Acquisition and Linguistic Theories. Amsterdam: Benjamins, 67-92.

Bybee, J. \& Slobin, D. I. (I982). Rules and schemas in the development and use of English past tense. Language 58, 265-89.

Bybee, J. \& Moder, C. L. (1983). Morphological classes as natural categories. Language 59, $25 \mathrm{I}-70$.

Clahsen, H. \& Rothweiler, M. (I 992). Inflectional rules in children's grammars: evidence from the development of participles in German. Morphology Yearbook, $\mathrm{I}-34$.

Clahsen, H., Rothweiler, M., Woest, A. \& Marcus, G. (I992). Regular and irregular inflection in the acquisition of German noun plurals. Cognition 45, $225^{-55}$.

Derwing, B. L. \& Baker, W. J. (I979). Recent research on the acquisition of English morphology. In P. Fletcher \& M. Garman (eds), Language Acquisition 209-24. Cambridge, Mass.: Cambridge University Press.

Fromkin, V. \& Rodman, R. (I974). An Introduction to Language. New York: Holt, Rinehart \& Winston.

Gawlitzek-Maiwald, I. ( I 994). How do children cope with variation in the input? The case of German plurals and compounding. In R. Tracy \& E. Lattey (ed), How tolerant is universal grammar? Essay on language learnability and language variation, 225-66. Tübingen: Niemeyer.

Hockett, C. F. (1954). Two models of grammatical description. Word Io, 2 IO-3I.

Innes, S. J. (I974). Developmental aspects of plural formation in English. Unpublished master's thesis. University of Alberta.

Janda, R. D. (1990). Frequency, markedness, and morphological change: on predicting the spread of noun plural $-s$ in modern High German and West Germanic. ESCOL ' 90 , I $36-53$.

Köpcke, K. M. (I 988). Schemas in German plural formation. Lingua 74, 303-35.

Köpcke, K. M. (1993). Schemata bei der Pluralbildung im Deutschen. Versuch einer kognitiven Morphologie. Tübingen: Narr.

Köpcke, K. M. \& Zubin, D. ( 1983 ). Die kognitive Organisation der Genuszuweisung zu den einsilbigen Nomen der deutschen Gegenwartssprache. Zeitschrift für germanistische Linguistik II, I66-82.

Lakoff, G. (1982). Categories and cognitive models. Berkeley Cognitive Science Report No. 2.

Linell, Per (1976). On the structure of morphological relations. Linguistische Berichte 44, I-29.

McClelland, J. L. (I988). Connectionist models and psychological evidence. Fournal of Memory and Language 27, 107-23.

MacWhinney, B. ( 1 978). The acquisition of morphophonology. Monographs of the Society for Research in Child Development $\mathbf{4 3}$, No. I.

MacWhinney, B. ( 1989). Competition and connectionism. In E. Bates \& B. MacWhinney (eds), The cross-linguistic study of sentence processing, 422-57. Cambridge: Cambridge University Press.

MacWhinney, B., Pleh, C. \& Bates, E. (1985). The development of sentence interpretation in Hungarian. Cognitive Psychology 17, I78-209.

Marcus, G. F., Pinker, S., Ullman, M., Hollander, M., Rosen, T. J. \& Xu, F. (r992). Overregularization in language acquisition. Monographs of the Society for Research in Child Development $\mathbf{5 7}$ (4, Serial No. 228).

Marcus, G. F., Brinkmann, U., Clahsen, H., Wiese, R. \& Pinker, S. (1995). German inflection: the exception that proves the rule. Cognitive Psychology 29, I 89-256.

Menn, L. \& MacWhinney, B. (1984). The repeated morph constraint: toward an exploration. Language 6o, 5I9-4I.

Mills, A. (1985). The acquisition of German. In D. I. Slobin (ed.), The cross-linguistic study of language acquisition. Vol. I : The Data, I4I-254. Hillsdale N.J.: Erlbaum.

Mugdan, J. (1977). Flexionsmorphologie und Psycholinguistik. Untersuchungen zu sprachlichen Regeln und ihrer Beherrschung durch Aphatiker, Kinder and Ausländer, am Beispiel der deutschen Substantivdeklination. Tübingen: Narr.

Park, T. Z. (1978). Plurals in child speech. Fournal of Child Language 5, 237-50. 


\section{KLAUS-MICHAEL KÖPCKE}

Pinker, S. (I99I). Rules of language. Science 253, 530-5.

Rosch, E. (I 977). Human categorization. In N. Warren (ed.): Advances in cross-cultural Psychology. London: Academic Press. $\mathrm{I}-49$.

Rosch, E. (I 978). Principles of categorization. In E. Rosch \& B. Lloyd (eds) Cognition and categorization, 27-48. Hillsdale, New Jersey: Erlbaum.

Rumelhart, D. \& McClelland, J. ( 1986 ). On learning the past tenses of English verbs. Implicit rules or parallel distributed processing? In J. McClelland, D. Rumelhart \& the PDP Research Group: Parallel distributed processing: explorations in the microstructure of cognition. Cambridge: MIT Press.

Slobin, D. I. ( I 973). Cognitive prerequisites for the development of grammar. In C. Ferguson \& D. I. Slobin (eds) Studies of child language development, I75-276.New York: Holt, Rinehart \& Winston.

Smith, E. \& Medin, D. (198I). Categories and concepts. Cambridge: Harvard University Press.

Solomon, M. B. (1972). Stem endings and the acquisition of inflections. Language Learning 22, $43-50$.

Stemberger, J. ( I98I). Morphology haplology. Language 57, 79 I-8I 7 .

Stemberger, J. \& MacWhinney, B. (I986). Form-oriented inflectional errors in language processing. Cognitive Psychology 18, 329-54.

Taylor, J. R. (1995). Linguistic categorization. Prototypes in linguistic theory. Oxford: Clarendon Press.

Veit, S. (I986). Das Verständnis von Plural- und Komparativformen bei (entwicklungs) dysgrammatischen Kindern im Vorschulalter. In G. Kegal et al. (eds), Sprechwissenschaft und Psycholinguistic. Opladen.

Zager, D. (I980). A real time process model of morphological change. Unpublished dissertation. State University of New York at Buffalo. 